\section{CPS-124 ADHERENCE TO SELECTIVE IMMUNOSUPPRESSIVE DRUG TREATMENTS IN PATIENTS WITH INFLAMMATORY IMMUNE MEDIATED DISEASES}

PA López Broseta, J Del Estal Jiménez, MÁ Roch Ventura*, A Sanjuan Belda, S Jornet Montaña, M Martín Marqués, M Mendoza Aguilera, E Esteve Pitarch, M Vuelta Arce, L Canadell Vilarrasa. Hospital Universitari Joan Xxiii, Pharmacy, Tarragona, Spain

\subsection{6/ejhpharm-2020-eahpconf.225}

Background and importance The paradigm of patients with immune mediated autoimmune diseases has changed with the introduction of biological medicines. The correct use of these drugs is necessary to guarantee their effectiveness.

Aim and objectives To analyse adherence in immune mediated diseases patients treated with selective immunosuppressive drugs (adalimumab or etanercept) and to establish a link with patient characteristics and treatment duration.

Material and methods A retrospective study in a third level hospital was conducted in patients receiving treatment with adalimumab or etanercept from January to December 2018. Adherence was measured via the medication possession ratio (MPR) over 1 year. Variables recorded were sex, age, pathology, previously taken biological drug treatments, treatment duration in days and number of auto-injectors. Statistical analysis of the data was made with SPSS.

Results The sample population was 146 patients, 55.5\% (81) men, mean age $53.58 \pm 12.47$ years, and $55.5 \%$ were treated with adalimumab, 39.7\% with etanercept and 3.9\% with the biosimilar etanercept. Medium treatment duration was 5.07 \pm 3.09 years. The main pathologies and frequency were: rheumatoid arthritis in $32.2 \%$ (47) of patients, spondyloarthropathy in $18.5 \%$ (27), psoriatic arthritis in $17.8 \%$ (26), psoriasis in $13.7 \%$ (20), Crohn's disease in 11\% (16), ulcerative colitis in $4.8 \%$ (7) and other pathologies in $2.1 \%$ (3). Regarding adherence, the overall rate was $89.3 \%$. For each patient group, adherence was $86.24 \%$ in patients with rheumatoid arthritis, $89.36 \%$ in patients with spondyloarthropathy, $94.5 \%$ in patients with psoriatic arthritis, $84.11 \%$ in patients with psoriasis, 94.63\% in patients with Crohn's disease, $93.01 \%$ in patients with ulcerative colitis, $84.38 \%$ in patients with Verneuil's disease and $84.11 \%$ in patients with systemic lupus erythematosus. In total, $78.1 \%$ (114) of all patients were adherent (MPR $\geq 80 \%$ ). We did not observe statistically relevant associations between any of variables except for lower adherence to treatment and longer treatment duration $(p=0.038)$.

Conclusion and relevance Patients had good adherence to selective immunosuppressant treatments according to the MPR method. Sex, pathology or drug type were not related to absence of adherence. However, lack of adherence was observed the longer treatment lasted, which implies that it would be useful to have closer pharmacotherapeutic monitoring of this kind to reinforce adherence in patients.

\section{REFERENCES AND/OR ACKNOWLEDGEMENTS}

No conflict of interest.

\section{CPS-125 ACCEPTANCE OF PHARMACOKINETIC RECOMMENDATIONS FOR EVEROLIMUS IN RENAL TRANSPLANT PATIENTS}

A Rochina*, S Gutiérrez, A González, A García, L Soriano, A Navarro. Hospital General Universitario Elche, Hospital Pharmacist, Elche, Spain

10.1136/ejhpharm-2020-eahpconf.226
Background and importance Pharmacokinetic monitoring of the transplanted patient is essential to keep blood concentrations of immunosuppressive drugs in range, and to reduce the risk of organ rejection and the adverse effects associated with these drugs.

Aim and objectives To assess the degree of acceptance by the nephrology service of recommendations made by the clinical pharmacokinetics unit after monitoring everolimus blood concentrations at a third level general university hospital.

Material and methods This was a retrospective observational study in renal transplant patients with at least two everolimus determinations between January 2016 and September 2019. Patients were identified from the Gestlab programme and data collected were: age, sex, date of testing, concomitant immunosuppressive treatment, blood concentrations and pharmacokinetic recommendations. The number of blood determinations per patient, percentage of pharmacokinetic recommendations accepted by the physician and the proportion of values lower and higher than the established therapeutic range were evaluated; the target therapeutic interval for monotherapy is 6-10 $\mathrm{ng} / \mathrm{mL}$ and in combination with calcineurin inhibitors is 3-8 $\mathrm{ng} / \mathrm{mL}$.

Results Pharmacokinetic monitoring was performed in 49 patients, 59\% men, with an average age of $60 \pm 12$ years and an average of $9 \pm 5.3$ everolimus determinations. In $65.3 \%$ of patients, treatment was with everolimus and tacrolimus simultaneously. A total of 443 samples were analysed, with a dose adjustment required in $34.7 \%$. The average everolimus percentages lower and higher than the target range were $23 \%$ and $11.3 \%$, respectively. The dosing recommendations of these patients were accepted in $69 \%$ of cases. After this adjustment, $66.1 \%$ of patients tested showed drug concentrations in range. Of the total recommendations not accepted, $31 \%$ of medical actions differed from the recommendation in the prescribed final dosing regimen.

Conclusion and relevance During the study period, posology individualisation was necessary in almost 35\% of the analyses performed by the clinical pharmacokinetics service, with the pharmacokinetic recommendations accepted by the prescriber in more than $60 \%$ of cases.

\section{REFERENCES AND/OR ACKNOWLEDGEMENTS}

No conflict of interest.

\section{CPS-126 A POPULATION PHARMACOKINETIC MODEL OF ADALIMUMAB IN A COHORT OF PAEDIATRIC PATIENTS WITH INFLAMMATORY BOWEL DISEASE: A PRELIMINARY ANALYSIS}

${ }^{1} \mathrm{M}$ Miarons Font, ${ }^{2} \mathrm{JG}$ Sánchez Hernandez*, ${ }^{3} \mathrm{JS}$ Pérez Blanco, ${ }^{1} \mathrm{~S}$ Clemente Bautista ${ }^{2} \mathrm{~N}$ Rebollo Diaz, ${ }^{4} \mathrm{O}$ Segarra Cantón, ${ }^{1} \mathrm{MJ}$ Cabañas Poy, ${ }^{5} \mathrm{R}$ Torres Peral, ${ }^{1} \mathrm{MQ}$ Gorgas, ${ }^{2}$ MJ Otero. ${ }^{1}$ Hospital Universitario Vall D'hebron, Pharmacy Department, Barcelona, Spain; ${ }^{2}$ Complejo Asistencial Universitario De Salamanca, Pharmacy Department, Salamanca, Spain; ${ }^{3}$ University of Salamanca, Department of Pharmaceutical Sciences, Salamanca, Spain; ${ }^{4}$ Hospital Universitario Vall D'hebron, Paediatric Gastroenterology Unit, Barcelona, Spain; ${ }^{5}$ Complejo Asistencial Universitario De Salamanca, Paediatric Gastroenterology Unit, Salamanca, Spain

\subsection{6/ejhpharm-2020-eahpconf.227}

Background and importance Therapeutic drug monitoring is useful to optimise adalimumab therapy in patients with inflammatory bowel disease (IBD). 
Aim and objectives The objective of this study was to perform a preliminary pharmacokinetic (PK) model of adalimumab to evaluate covariates potentially responsible for the PK variability in paediatric patients with IBD.

Material and methods A 3 year retrospective multicentre study was performed including children and adolescent ( $\leq 18$ years) diagnosed with IBD and treated with adalimumab. Demographic and clinical data were collected, including serum albumin, C reactive protein and faecal calprotectin. Pre-dose serum samples were carried out before administration. Adalimumab concentrations and anti-adalimumab antibodies (AAA) were determined by ELISA. The model was developed in NONMEM V.7.4 by approximating the non-linear mixed effects models. The first order conditional estimation method with interaction (FOCEI) was used for model building. Concentrations below the lower limit of quantification (LLOQ) were set to LLOQ/2. Body weight (WGT) was included in the PK parameters following an allometric relationship.

Results Twenty-three paediatric patients (10 women) were included, 3 were diagnosed with ulcerative colitis and 20 with Crohn disease. Median age (range) was 14.0 (5-18) years and weight $55.9(20.4-80) \mathrm{kg}$. A total of 75 concentrations $(2<$ LLOQ) were determined, with a medium concentration of $10.72(0.1-24.7) \mu \mathrm{g} / \mathrm{mL}$. Median (range) serum albumin level was $4.0(2.8-5.0) \mathrm{g} / \mathrm{dL}$. Only one patient developed AAA. Population PK model (PopPK): a one compartment with first order absorption and elimination described adequately the serum adalimumab concentration-time data. The absorption rate constant was fixed $(\mathrm{Ka}=0.008 /$ hour $)$ according to Sharma et al. Among the clinical variables analysed, only albumin was significant on the apparent clearance (CL/F). The final PopPK model in the absence of AAA was as defined as: $\mathrm{V} /$ $\mathrm{F}=11.30 \times(\mathrm{WGT} / 56 \mathrm{~kg})$ and $\mathrm{CL} / \mathrm{F}(\mathrm{L} /$ day $)=0.42 \times($ albumin $/ 4 \mathrm{~g} /$ $\mathrm{dL})^{-2.32} \times(\mathrm{WGT} / 56 \mathrm{~kg})^{0.75}$. Covariate analysis reduced the interindividual variability associated with CL (IIVCL) from $34.1 \%$ to $21.3 \%$. Proportional residual error estimated was $28.4 \%$.

Conclusion and relevance Adalimumab PK in paediatric patients with IBD was best described by a one compartment model with first order absorption and elimination. WGT was included in the PK parameters following an allometric relationship. Albumin showed statistically significant differences on adalimumab $\mathrm{CL} / \mathrm{F}$, explaining $62.5 \%$ of its variability.

\section{REFERENCES AND/OR ACKNOWLEDGEMENTS}

1. Sharma S, et al. Inflamm Bowel Dis 2015;21:783-792.

No conflict of interest.

\section{CPS-127 ECONOMIC IMPACT OF INTENSIFICATION REGIMENS IN INFLAMMATORY BOWEL DISEASE}

L Ulacia Epelde*, A Arrondo Velasco, J Polo Garcia, G Pinilla Lebrero, JA Illodo Becerra, M Calvo Arbeloa, A Rodríguez Esquíroz, D Tejada Marín, P Aldave Cobos, MT Sarobe Carricas, JJ Elizondo Armendariz. Complejo Hospitalario De Navarra, Farmacia, Pamplona, Spain

\subsection{6/ejhpharm-2020-eahpconf.228}

Background and importance Biological treatments have improved the therapeutic options for inflammatory bowel disease (IBD) and have shown high clinical efficacy. Nevertheless, some patients do not respond to initial treatment or present loss of response over time. To prevent the loss of efficacy, treatment intensification has been employed, usually applied empirically based on the clinical condition of the patient and biochemical parameters. The introduction of tumour necrosis factor antagonist (anti-TNF) monitoring in clinical practice allows a more accurate selection of strategies.

Aim and objectives To analyse the number of patients receiving treatment with a biological agent for IBD and requiring an intensification regimen, including increasing dosage or shortening the administration interval, and to evaluate the economic impact of this intensification strategy.

Material and methods This was a retrospective observational study in patients diagnosed with IBD and under an intensified regimen of a biological agent. The cost per patient was estimated based on the extrapolation of the price of each medication for 1 year of treatment. In addition, the difference in costs per patient and year for each treatment and the total economic impact were calculated.

Results A total of 549 patients with IBD were receiving a biological treatment and 239 required an intensification regimen (table 1).

Conclusion and relevance Intensification regimens, including

\begin{tabular}{|c|c|c|c|c|c|}
\hline Drug & $\begin{array}{l}\text { Intensification } \\
\text { regimen }\end{array}$ & $\begin{array}{l}\text { No patients (\% } \\
\text { intensifications } \\
\text { per drug) }\end{array}$ & $\begin{array}{l}\text { Patient } \\
\text { annual } \\
\text { cost } \\
(€)\end{array}$ & $\begin{array}{l}\text { Difference } \\
\text { with } \\
\text { respect to } \\
\text { standard } \\
\text { regimen } \\
(€)\end{array}$ & $\begin{array}{l}\text { Incremental } \\
\text { annual total } \\
\text { cost }(€)\end{array}$ \\
\hline Adalimumab & $40 \mathrm{mg} \mathrm{q} 1$ week & $34(18)$ & 4860 & 2430 & 82620 \\
\hline Golimumab & $\begin{array}{l}100 \mathrm{mg} \mathrm{q4} \\
\text { weeks }\end{array}$ & $13(52)$ & 11082 & 725 & 9425 \\
\hline \multirow[t]{4}{*}{ Ustekinumab } & q8 weeks & $52(68)$ & 16063 & 5362 & 278824 \\
\hline & q6 weeks & $9(12)$ & 21425 & 10725 & 96525 \\
\hline & q5 weeks & $1(1)$ & 25700 & 15000 & 15000 \\
\hline & q4 weeks & $13(17)$ & 32125 & 21425 & 278525 \\
\hline \multirow[t]{2}{*}{ Vedolizumab } & q6 weeks & $14(19)$ & 13791 & 3452 & 48328 \\
\hline & q4 weeks & $16(22)$ & 20678 & 10339 & 165424 \\
\hline \multirow[t]{3}{*}{ Infliximab } & $\begin{array}{l}10 \mathrm{mg} / \mathrm{kg} \text { q8 } \\
\text { weeks }\end{array}$ & $77(43)$ & 6341 & 3170 & 244090 \\
\hline & $\begin{array}{l}5 \mathrm{mg} / \mathrm{kg} \text { q6 } \\
\text { weeks }\end{array}$ & $9(5)$ & 4229 & 1058 & 9522 \\
\hline & $\begin{array}{l}5 \mathrm{mg} / \mathrm{kg} \mathrm{q} 4 \\
\text { weeks }\end{array}$ & $1(1)$ & 6341 & 3170 & 3170 \\
\hline Total & & 239 & & & 1231453 \\
\hline
\end{tabular}

increasing dosage or shortening the administration intervals, were frequent in our hospital, both for anti-TNF and for other biological agents used for the treatment of IBD. These strategies involve an important economic impact, as well as a high risk of infection for patients. Intensification should be guided by pharmacokinetic monitoring. More studies are needed to validate therapeutic algorithms that allow optimisation of resources for all biological agents used.

\section{REFERENCES AND/OR ACKNOWLEDGEMENTS}

No conflict of interest. 